\title{
Hemodiyaliz Tedavisi Alan Hastaların Umut Düzeyleri, Semptom Kontrolü ve Tedaviye Uyumlarının Değerlendirilmesi
}

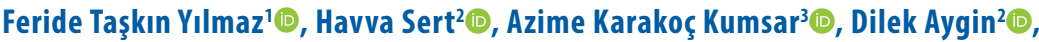 \\ Savaş Sipahi ${ }^{4} \oplus$, Ahmet Bilal Genç ${ }^{4}$
}

'Sivas Cumhuriyet Üniversitesi Suşehri Sağlık Yüksekokulu, Sivas, Türkiye ${ }^{2}$ Sakarya Üniversitesi, Sağlık Bilimleri Fakültesi, Sakarya, Türkiye ${ }^{3}$ Biruni Üniversitesi, Sağlık Bilimleri Fakültesi, İstanbul, Türkiye ${ }^{4}$ Sakarya Üniversitesi Eğitim ve Araştırma Hastanesi Nefroloji Kliniği, Sakarya, Türkiye

Feride Taşkın Yılmaz, Doç. Dr. Havva Sert, Dr. Öğr. Üyesi Azime Karakoç Kumsar, Dr. Öğr. Üyesi Dilek Aygin, Doç. Dr. Savaş Sipahi, Prof. Dr. Ahmet Bilal Genç, Uzm. Dr.

İletişim:

Doç. Dr. Feride Taşkın Yılmaz Sivas Cumhuriyet Üniversitesi Suşehri Sağlık Yüksekokulu, Sivas, Türkiye

Tel: +90346311 $5223-120$

E-Posta: feride_taskin@hotmail.com

Gönderilme Tarihi : 27 Şubat 2018

Revizyon Tarihi : 25 Haziran 2018

Kabul Tarihi : : 26 Haziran 2018

\section{ÖZET}

Amaç: Hemodiyaliz tedavisi alan hastalar, hastalığın ilerleyici ve tedavi yöntemlerinin kısıtlayııı olması nedeniyle umutsuzluk yaşayabilir. Bu durum, hastaların semptom kontrolünü ve tedaviye uyumunu güçleștirebilmektedir. Araștırma hemodiyaliz tedavis alan hastaların umut düzeylerini, semptom kontrolünü ve tedaviye uyumlarını belirlemek, umut düzeyi ile semptom kontrolü ve tedaviye uyum arasında ilişkiyi saptamak amacıyla yapılmışıı.

Yöntem: Tanımlayııı ve ilişki arayııı tasarımda gerçekleştirilen araştırmanın örneklemine 73 hasta dâhil edilmiştir. Veriler, hasta tanılama formu, Hert Umut Ölçeği veKronik Hemodiyaliz Hastalarında Diyaliz Semptom İndeksi ile toplanmıştır. Verilerin değerlendirmesinde yüzdelik, ortalama, Pearson korelasyon analizi, Mann-Whitney U testi ve Kruskal-Wallis testi kullanılmıştır.

Bulgular: Hastaların Hert Umut Ölçeği puan ortalamasının ortalama değerin üzerinde ve semptomlara bağlı sıkıntı düzeylerinin düşük olduğu saptanmıştır. Hastaların \%83,6's'snın doktorun önerdiği tarihte düzenli olarak sağlık kontrollerine gittiği, \%94,5'inin ilaçlarını düzenli kullandığı, \%56,2'sinin hastalı̆ııın yönetimi konusunda diyetini düzenli uyguladığı, $\% 78,1^{1}$ inin sıvı kısıtlaması ya da sıvı alımına dikkat ettiği belirlenmiștir. Hert Umut Ölçeği puan ortalaması ile Kronik Hemodiyaliz Hastalarında Diyaliz Semptom Indeksi puan ortalaması arasında negatif yönde ilişki saptanmıştı. Umut düzeyi yüksek olan hastaların doktorun önerdiği tarihte düzenli olarak sağlık kontrollerine gitme, kan tahlili, kan basıncı ölçümü gibi rutin kontrolleri eksiksiz yaptırma, hastalığının yönetimi konusunda diyetini düzenli uygulama ve SIVI kısıtlaması ya da SIVı alımına dikkat etme gibi tedaviye uyum oranlarının daha iyi olduğu bulunmuştur.

Sonuç: Hemodiyaliz tedavisi alan hastaların umut düzeyi arttıkça, semptomlarla ilişkili sıkıntı düzeylerinin azaldığı ve tedaviye uyumlarının yükseldiği belirlenmiştir.

Anahtar sözcükler: Hemodiyaliz, semptomlar, tedavi uyumu, yaşam beklentisi

\section{EVALUATION OF HOPE, SYMPTOM CONTROL, AND MEDICATION COMPLIANCE/ADHERENCE IN HEMODIALYSIS PATIENTS}

\section{ABSTRACT}

Objectives: Hemodialysis patients may experience hopelessness since their disease is progressive, and requires restrictive treatment methods. This situation may make it difficult to control symptoms and medication compliance. The current study aimed to determine hope, symptom control and medication compliance in hemodialysis patients, and to investigate the associations between the level of hope, symptom control, and medication compliance.

Methods: The sample of this descriptive and correlational study consisted of 73 patients. Data were collected using the patient identification form, the Herth Hope Index, and the Dialysis Symptom Index in Chronic Hemodialysis Patients. Data were analyzed using percentiles, means, Pearson correlation, Mann-Whitney U test, and Kruskal-Wallis test.

Results: Mean Herth Hope Index score was above the average value, and the level of symptom-related distress was low. Among the patients, $83.6 \%$ attended routine follow-up visits on dates recommended by their doctors, $94.5 \%$ regularly used their medicine, $56.2 \%$ adhered to their diet for disease management, and $78.1 \%$ adhered to fluid restriction or monitored liquid intake. There was a negative correlation between the mean Herth Hope Index score and the mean Dialysis Symptom Index in Chronic Hemodialysis Patients score. It was found that patients who had high levels of hope had attended routine follow-up visits on the dates that were recommended by their doctors; ensured that caregivers performed routine controls such as blood analysis, blood pressure, etc.; and exhibited medication compliance (adherence to diet and liquid restriction for disease management) at better rates.

Conclusion: It was determined that symptom-related distress reduced, and medication compliance increased as the level of hope increased in hemodialysis patients.

Keywords: Hemodialysis, symptoms, medication compliance, life expectancy 
$\mathrm{H}$ emodiyaliz, kronik böbrek yetmezliğinin tedavisinde en çok tercih edilen renal replasman tedavi yöntemlerinden biridir (1). Türkiye'de 2016 yılı sonunda renal replasman tedavisi gerektiren son dönem kronik böbrek hastalığı nokta prevalansının milyon nüfus başına 933,1 olduğu, prevalansın yıllar içinde kararlı bir şekilde artış gösterdiği ve renal replasman tedavisi alan son dönem böbrek yetmezliği hastalarının \%76,12'sinihemodiyaliz tedavisinin oluşturduğu tespit edilmiştir (2).

Hemodiyaliz tedavisi ile hastaların sağlıklı kalması, yaşam kalitesinin arttırılması ve mortalite ve morbidite oranlarının azaltılması hedeflenmektedir $(3,4)$. Bununla birlikte hemodiyaliz tedavisi alan hastalarda yorgunluk, ağrı, mide bulantısı, kusma, iştahsızlık, kas krampları, uyku problemleri, ciltte kuruluk, kaşıntı, huzursuzluk, sinirlilik, depresyon gibi fiziksel veya psikolojik birçok semptom gözlemlenmektedir (5-8). Bu semptomlar bireylerin günlük yaşam aktivitelerini ve öz bakım gücünü olumsuz etkileyebilmektedir (9).

Hemodiyaliz tedavisi böbrek hastalarının yaşam süresini uzatan bir yöntemdir (9). Ancak, hemodiyaliz tedavisi diyet, ilaç kullanımı gibi birtakım tedavi yöntemlerine, tedavinin getirdiği pek çok kısıtlamalara ve bu kısıtlayıcı yaşam tarzına uyumu zorunlu kılmaktadır (10). Ek olarak hemodiyaliz tedavisi, haftanın belirli günleri ortalama 4-6 saat süren tedavi programlarına ve cihaza bağımlı olma, makine alarmlarının korku ve endişeye neden olması, cinsel fonksiyon bozuklukları, zaman ve iş gücü kaybı, rol ve fonksiyon kaybı, aile düzeninin bozulması gibi fiziksel, psikolojik, sosyal ve ekonomik bazı olumsuz etkilereneden olabilmektedir (11). Bu olumsuzluklar da hemodiyaliz hastalarında umutsuzluğa neden olabilmektedir $(10,12,13)$.

Umut, kişinin geleceğe uyumu için ona güç veren, gelecekle ve yaşantısıyla ilgilenmesini ve hayatta anlam bulmasını sağlayan, etkili bir başa çıkma stratejisidir $(4,13)$. Pozitif bakışı ve iyi oluşu destekleme, fiziksel ve ruhsal iyilik halini geliştirmede önemli bir faktör olan umudun, yaşam kalitesini artırdığı belirtilmektedir. Umut, bireyin kendisini güvende hissetmesini ve gerçekle ilişki kurmasını sağlayan, motivasyonunu artıran, hastalık durumunda karamsarlık veya çaresizlik duygularını önleyen, tedaviye uyuma katkı sağlayan etkili bir baş etme mekanizması olarak görülmektedir $(13,14)$. Klinik tedavinin yoğun olduğu hemodiyaliz hastalarında umut durumunun değerlendirilmesi önem taşımaktadır. Literatürde, hemodiyaliz tedavisi alan hastalarda umudun psikososyal sorunların kontrolünde önemli bir etmen olduğu $(1,6)$, mortalite ve hastaneye tekrarlı yatışları etkilediği vurgusu yapılmaktadır
(15). Yapılan araştırmalarda, diyaliz hastalarının umut düzeylerinin iyi olmadığı $(10,16)$, bu durumun hemodiyaliz tedavisi alan hastaların hastalığa ve tedaviye uyumunu güçleştirebildiği belirlenmiştir (12).

Tedaviye uyum bireyin ilaçlarını alma, diyetini takip etme, yaşam şekli değişikliklerini uygulama gibi davranışlarının, sağlık personeli tarafından yapılan önerilere uygun olma düzeyi ile belirlenmektedir (17). Hemodiyaliz tedavisinde hastaların sıvı alınımını kısıtlaması, diyet önerilerini uygulaması, ilaçlarını düzenli kullanması ve planlanan aralıklarda öngörülen süre boyunca diyalize girmesi önemlidir (10, $18,19)$. Literatürde, hemodiyaliz hastalarında ilaç, sıvı ve diyete uyumsuzluğun yaygın olduğu belirtilmektedir (19, 20). Sivı retansiyonu, fosfat retansiyonu, sekonder hiperparatroidizm, hipertansiyon, kronik anemi, hiperlipidemi ve kalp hastalıkları gibi komplikasyonların önlenmesi ve kontrolü açısından hemodiyaliz hastalarının önerilen yaşam tarzı ve tedaviye uyumları önemlidir (21).

Hemodiyaliz hastalarında umut ve tedaviye uyum; hastaların çaba gösterme davranışlarını, motivasyonlarını ve stresle baş etmelerini etkilemesi açısından, hemşirelik bakımında ele alınması gereken önemli konulardan biridir $(1,11)$. Hemşireler, hastaların geleceğiyle ilgili yaşadığı belirsizlikleri, hastalık ve tedaviyle ilgili yaşadığı sorunları ortadan kaldıracak, tedaviye uyumu artıracak, tedavinin devamlılığını ve sorunlarla etkili bir şekilde baş etmesini sağlayacak güç olarak tanımlanan umudu desteklemede anahtar rol oynamaktadır (22).

Literatürde, hemodiyaliz hastalarında umut düzeylerinin incelendiği araştırmalar bulunmakla birlikte $(1,4,10,13,16)$, umudun semptom kontrolü ve tedaviye uyum ile ilişkisini inceleyen araştırmaya rastlanmamıştır. Başka hastalığı olan bireylerle yapılan çalışmalarda, umudun semptom kontrolünü ve tedaviye uyumu etkilediği; umut düzeyi yüksek hastaların daha az semptom yaşadıkları ve tedaviye daha iyi uyum gösterdiği saptanmıştır $(23,24)$. Bu bağlamda, hemodiyaliz hastalarında umut düzeyinin belirlenmesinin, semptom kontrolü ve tedaviye uyum ile aralarındaki ilişkinin saptanmasının hem hastalar hem de sağlık profesyonelleri için tedavi ve bakımda yeni ya da farklı uygulamaların planlanması açısından önemli olacağı düşünülmektedir.

\section{Gereç yöntem}

Araştırmanın amacı ve tipi

Araştırma, hemodiyaliz tedavisi alan hastaların umut düzeylerini, semptom kontrolünü ve tedaviye uyumlarını belirlemek amacıyla tanımlayıcı ve kesitsel olarak yapılmıştır. 


\section{Araştırma soruları}

Araştırmanın amacından yola çıkılarak aşağıdaki araştırma sorularına yanıt aranmıştır.

- Hemodiyaliz hastalarının umut düzeyi nedir?

- Hemodiyaliz hastalarının semptomlarla ilişkili sıkıntı yaşama düzeyleri nedir?

- Hemodiyaliz hastalarının tedaviye uyumları nasıldır?

- Hemodiyaliz hastalarının umut düzeyleri ile semptom kontrolü arasında bir ilişki var mıdır?

- Hemodiyaliz hastalarının umut düzeyleri ile tedaviye uyum arasında bir ilişki var mıdır?

\section{Araştırmanın evreni ve örneklemi}

Araştırmanın evrenini 01 Eylül 2016-31 Mayıs 2017 tarihleri arasında bir üniversite hastanesinin Hemodiyaliz Ünitesi'ne kayıtlı 68 hasta ile hastane içinden farklı servislerden gelen 53 hasta olmak üzere toplam 121 hasta oluşturmuş̧ur. Araştırmanın örneklemine hemodiyaliz nedeniyle komplikasyonu bulunmayan, sözel iletişim engeli bulunmayan, yeterli bilişsel düzeye sahip, 18 yaş üzeri ve araştırmaya katılmayı kabul eden Hemodiyaliz Ünitesi'ne kayıtlı 62 ve hastane içinden farklı servislerden gelen 11 hasta olmak üzere 73 hasta dâhil edilmiştir.

Araştırma Türkiye'nin Batı Karadeniz Bölgesi'nde bir ilde bulunan, 15 yataklı hemodiyaliz ünitesine sahip tek bir üniversite hastanesinde yapılmıştır. Hemodiyaliz ünitesinde toplam 12 hemşire ve altı hekim görev yapmaktadır. Hemodiyaliz ünitesi randevu sistemine göre hafta içi ve Cumartesi günü 08:00-18:00 saatleri arasında hastalara hizmet vermektedir. Hastalara hemodiyaliz ünitesinde daha önce konu ile ilgili herhangi bir eğitim verilmemiştir.

\section{Veri toplama araçları}

Veriler hasta tanılama formu, Herth Umut Ölçeği ve Kronik Hemodiyaliz Hastalarında Diyaliz Semptom İndeksi kullanılarak elde edilmiştir.

Hasta Tanılama Formu; Araştırmacılar tarafından literatür incelemesi doğrultusunda hazırlanan form, kişisel özelliklerin (yaş, cinsiyet, medeni durum, eğitim durumu, çaıışma durumu, kiminle yaşadığı, sosyal güvence varlığı, sigara kullanma durumu vb.), hastalık ile ilgili özelliklerin (hastalık süresi, hastalığa neden olan faktörler, hemodiyaliz tedavi süresi, başka kronik hastalık varlığı, transplantasyon öyküsü, hastalık hakkında bilgi alma durumu, günlük ihtiyaçlarını karşılayabilme durumu, genel sağlık değerlendirmesi, sıkıntı ve duygularını paylaşabileceği arkadaş ya da aile bireyi varlığı vb.) ve tedaviye uyum ile ilgili bilgilerin (sağlık kontrolüne gitme durumu, kan tahlili, kan basıncı ölçümü gibi rutin kontrolleri yaptırma durumu, ilaçları düzenli kullanma durumu, hastalığınızın yönetimi konusunda diyetini, sıvı alımını ve sıvı kısıtlamasını uygulama durumu, baş ağrısı, bulantı, uykusuzluk, kaşıntı gibi yakınmalarda tutumu) sorgulandığı 30 sorudan oluşmaktadır $(17,18,25-27)$.

Herth Umut Ölçeği: Kronik düzeyde hasta bireylerin umut düzeylerini belirlemeye yönelik olarak Kaye Herth tarafından 1991 yılında geliştirilmiş, Aslan ve arkadaşları (2007) tarafından Türk toplumuna uyarlanmıştır. Ölçek 30 maddeden oluşmaktadır. Her bir madde karşısında "Hiç uygun değil", "Nadiren uygun", "Bazen uygun" ve "Her zaman uygun" şeklinde dört seçenek vardır. Bunlara karşılık gelen puanlar sırasıyla 0, 1, 2, 3 şeklindedir. Ölçek üç alt ölçekten oluşmaktadır. Bunlar "Geçici olma ve gelecek", "Olumlu hazır oluşluk ve beklenti" ve "Kendisi ve çevresindekilerle arasındaki bağlar" alt ölçekleridir. "Geçici olma ve gelecek" alt boyutu umudun kognitif-geçici boyutunu; olumlu hazır oluşluk ve beklenti" alt boyutu umudun duygusal-davranışsal boyutunu; "kendisi ve çevresindekilerle arasındaki bağlar alt boyutu ise umudun ilişkiler ve içinde bulunulan şartlarla ilgili durumunu ölçmektedir. Ölçeğin toplam puanı bütün maddelere verilen cevapların puanlarının toplanmasıyla, alt ölçeklerin puanı, her bir alt ölçeğe karşılık gelen maddelere verilen cevapların puanlarının toplanmasıyla hesaplanmaktadır. Toplam umut puanı 0-90, her bir alt ölçek toplam puanı ise 0-30arasında değişmektedir. Yüksek puanlar, umudun yüksek olduğunu göstermektedir (28). Araştırmada ölçeğin Cronbach alfa değeri 0,84 olarak bulunmuştur.

Kronik Hemodiyaliz Hastalarında Diyaliz Semptom Indeksi: Weisbord ve ark. tarafından 2004 yılında geliştirilmiş olup Türkçe geçerlik güvenirlik araştırması Önsöz ve Usta Yeşilbalkan (2013) tarafından yapılmıştır. Fiziksel ve emosyonel semptomlarla ilişkili yaşanan sıkıntı düzeyini ölçmek amacıyla hemodiyaliz hastalarında geliştirilen ölçek 30 maddeden oluşmaktadır. Yanıtlar 5'li Likert ölçeği ile elde edilmektedir. Son yedi gün içerisinde yaşanan semptomlar evet-hayır olarak cevaplanıp eğer evet ise bu semptomun ne kadar etkilediği, $5^{\prime}$ li Likert olarak 1=hiç, $2=$ biraz, $3=$ bazen, $4=c ̧ o k$ az, $5=$ çok fazla şeklinde değerlendirmeye sahiptir. Elde edilen puanlar toplanarak toplam ölçek puanı elde edilmektedir. Bu değer 0-150 arasında değişmektedir. "0" değeri semptomun olmadığını göstermektedir. Cevaplara verilen toplam puanların 150 puana doğru artış göstermesi semptomların etkisinin yükseldiğini göstermektedir (29). Araştırmada ölçeğin Cronbach alfa değeri 0,90 olarak tespit edilmiştir. 


\section{Uygulama}

Veriler araştırmacılar tarafından rahat görüşebilecek bir ortamda hemodiyaliz tedavisi sırasında hastalar ile yüz yüze görüşülerek toplanmıştır. Veri formlarının doldurulması yaklaşık 25-30 dakika sürmüştür.

\section{Etik boyut}

Verileri toplamadan önce bir üniversitenin etik kurulundan (Karar no: 2016-02/01) yazılı izin alınmıştır. Ayrıca, araştırmada yer alacak her hasta araştırmanın içeriği ve katılımın gönüllü olması hususunda bilgilendirilmiş ve sözlü onamları alınmıştır.

\section{Verilerin değerlendirilmesi}

Veriler, SPSS 22,0 paket programında yorumlanmıştır. Hastaların sosyodemografik ve hastalık özellikleri ile yaşadıkları semptomların dağılımı yüzdelik ve ortalama testi ile, Hert Umut Ölçeği ve Kronik Hemodiyaliz Hastalarında Diyaliz Semptom Indeksi puan ortalamaları arasındaki ilişki Pearson korelasyon analizi ile değerlendirilmiştir. Hastaların tedaviye uyum durumları ile Hert Umut Ölçeği puan ortalamaları arasındaki ilişkinin incelenmesinde Mann-Whitney $\mathrm{U}$ testi ve Kruskal-Wallis testi kullanılmıştır. İstatistiksel değerlendirmede anlamlılık $p<0,05$ olarak değerlendirilmiştir.

\section{Araştırmanın sınırlılıkları}

Araştırmanın tek bir üniversite hastanesine belirli zaman diliminde başvuran ve araştırmaya katılmayı kabul eden hemodiyaliz tedavisi alan hastalar ile yürütüldüğü için sonuçlarının kendi evrenine genellenebilir olması önemli bir sınırlılığıdır. Ayrıca, hastaların umut düzeyi, semptom kontrolü ve tedaviye uyumları konusunda elde edilecek bilgiler öz bildirimine dayalıdır. Ayrıca, çalışmada hastaların umut düzeylerini ve tedaviye uyumlarını etkileyebilecek faktörler incelenmemiştir.

\section{Bulgular}

Araştırmaya dâhil edilen hastaların yaş ortalaması $54,48 \pm 13,56$ yıl olup, $\% 52,1$ 'i erkektir. Katılımcıların $\% 58,9$ 'u ilkokul mezunu, $\% 67,1$ 'i evli, $\% 6,8$ 'i yalnız yaşamakta ve \%28,8'i herhangi bir işte çalışmamaktadır. Hastaların \%54,8'i ilçe merkezinde yaşamakta olup, $\% 16,4$ 'ünün sosyal güvencesi bulunmamakta ve $\% 16,4$ 'ü halen sigara içmektedir.

Hastaların hastalık süresi ortalaması $7,86 \pm 6,73$ yıl ve hemodiyaliz tedavi süresi ortalaması 2,84 $\pm 0,43$ yıldır. Katılımcıların \%87,7'si haftada üç kez hemodiyaliz tedavisi görmektedir. Hastaların \%26'sı diyabet ve \%21,9'u hipertansiyon nedeniyle böbrek yetmezliği geliştiğini, $\% 47,9^{\prime}$ u başka bir kronik hastalığının bulunduğunu ve sadece \%65,8'i hastalığı hakkında bilgi sahibi olduğunu belirtmiştir. Hastaların \%35,6'sı transplantasyon beklediğini, $\% 56,2$ 'si ise transplantasyon planlamadığını ifade etmiştir. Günlük ihtiyaçlarını tek başına karşılayamayan hastaların oranı \%17,8'dir. Katılımcıların \%52,1'i genel sağlığını iyi düzeyde değerlendirmiştir (Tablo 1).

Tablo 2'de hastaların Hert Umut Ölçeği ve Kronik Hemodiyaliz Hastalarında Diyaliz Semptom Indeksi puan ortalamaları dağılımı verilmiştir. Buna göre, katıımcıların Hert Umut Ölçeği puan ortalamasının 60,56 20,28 olduğu ve en yüksek alt boyut puan ortalamasının kendisi ve çevresindekilerle arasındaki bağlar alt boyutu $(21,78 \pm 7,43)$ olduğu belirlenmiştir. Hastaların Kronik Hemodiyaliz Hastalarında Diyaliz Semptom Indeksi puan ortalamasının ise, $32,54 \pm 29,12$ olduğu bulunmuștur. Hert Umut Ölçeği ve Kronik Hemodiyaliz Hastalarında Diyaliz Semptom Indeksi arasında negatif yönde ve düşük düzeyde anlamlı ilişki olduğu saptanmıştır ( $r=-0,351, p=0,002)$.

Hemodiyaliz tedavisi alan hastaların yaşadıkları semptomlar incelendiğinde, yorgun hissetme veya enerjide azalma $(\% 57,5)$, ayaklarda uyuşukluk veya karıncalanma $(\% 50,7)$ ve ağız kuruluğu $(\% 46,6)$ belirtilerini daha fazla yaşadığı belirlenmiştir (Tablo 3).

Tablo 4'te hastaların tedaviye uyumuna ilişkin bilgiler verilmiştir. Buna göre, hastaların \%83,6'sı doktorun önerdiği tarihte düzenli olarak sağlık kontrollerine gittiğini, $\% 87,7$ 'si doktor istediği takdirde kan tahlili, kan basıncı ölçümü gibi rutin kontrolleri eksiksiz yaptırdığını, \%94,5'i ilaçlarını düzenli kullandığını, \%56,2'si hastalığının yönetimi konusunda diyetini düzenli uyguladığını, \%78, $1^{\prime i}$ sıvı kısıtlamasını ya da sıvı alımına dikkat ettiğini ve \%31,5'i baş ağrısı, bulantı, uykusuzluk, kaşıntı gibi yakınmalarda doktor ya da hemşiresini telefonla aradığını belirtmiştir.

Hastaların Herth Umut Ölçeği puan ortalaması ile tedaviye uyumları arasındaki ilişsi incelendiğinde; umut düzeyi yüksek olan hastaların doktorun önerdiği tarihte düzenli olarak sağlık kontrollerine gitme $(p=0,007)$, kan tahlili, kan basıncı ölçümü gibi rutin kontrolleri eksiksiz yaptırma $(p=0,001)$, hastalığının yönetimi konusunda diyetini düzenli uygulama $(p=0,039)$ ve sIVı kısıtlamasına ya da SIVI alımına dikkat etme $(p=0,045)$ gibi tedaviye uyum oranlarının daha iyi olduğu bulunmuştur $(p<0,05)$ (Tablo 4). 
Tablo 1. Hastaların hastalık ve hemodiyaliz tedavisi ile ilgili özellikleri $(n=73)$

Özellikler

Sayı (n) Yüzde (\%)

Yaş (yıl) $($ Ort \pm SS)

$54,48 \pm 13,56$

$(\min =21, \max =76)$

Hastalık süresi (yıl) (Ort \pm SS)

$7,86 \pm 6,73$

$(\min =1, \max =31)$

Hemodiyaliz tedavi süresi (yıl) (Ort \pm SS)

$2,84 \pm 0,43$

$(\min =1, \max =3)$

\section{Haftada hemodiyaliz tedavisi gün sayısı}

1-2 kez

9

12,3

$3 \mathrm{kez}$

64

87,7

Hemodiyaliz tedavi süresi

4 saat

4 saat üzeri

65

89,0

Böbrek yetmezliğine neden olan hastalık

Akut böbrek yetmezliği

Diabetes mellitus

Hipertansiyon

Diğer*

Bilinmiyor

Başka kronik hastalık varığı

Evet

Hayır

Transplantasyon öyküsü

Başarısız transplantasyon

Transplantasyon bekliyor

Transplantasyon planlamıyor

Hastalığı hakkında eğitim alma durumu

Evet

Sağlık profesyoneli (doktor, hemşire)

Arkadaş/Komşu

Hayır

Genel sağlık değerlendirmesi

İyi

Orta

Kötü

Günlük intiyaçlarını tek başına karşılayabilme durumu

Evet

KIsmen

Hayır

Evde bakım ve tedavi ile ilgilenen birey varlığı

Evet

Hayır

Sıkıntı ve duygularını paylaşabileceği arkadaş ya da aile bireyi varlığı

Evet

$61 \quad 83,6$

Hayır

12

16,4

*Diğer: glomerulonefrit, pyelonefrit, polikistik böbrek
Tablo 2. Hastaların Herth Umut Ölçeği ve kronik hemodiyaliz hastalarında diyaliz semptom indeksi puan ortalamalarının dağlımı

\begin{tabular}{|c|c|c|c|c|}
\hline Ölçekler & $\begin{array}{c}\text { Alınabilecek } \\
\text { min-max } \\
\text { puan }\end{array}$ & $\begin{array}{l}\text { Alınan } \\
\text { min-max } \\
\text { puan }\end{array}$ & $O r t \pm S S$ & $r / p$ \\
\hline \multicolumn{5}{|l|}{ Herth Umut ÖIçeği } \\
\hline Geçici olma ve gelecek & $0-30$ & $2-30$ & $18,75 \pm 7,39$ & \\
\hline $\begin{array}{l}\text { Olumlu hazır oluşluk ve } \\
\text { beklenti }\end{array}$ & $0-30$ & $4-30$ & $20,02 \pm 7,00$ & \\
\hline $\begin{array}{l}\text { Kendisi ve çevresindekilerle } \\
\text { arasındaki bağlar }\end{array}$ & $0-30$ & $3-30$ & $21,78 \pm 7,43$ & \multirow{2}{*}{$\begin{array}{l}-0,351 \\
0,002^{\star}\end{array}$} \\
\hline Genel & $0-90$ & $13-90$ & $60,56 \pm 20,28$ & \\
\hline $\begin{array}{l}\text { Kronik Hemodiyaliz } \\
\text { Hastalarında Diyaliz } \\
\text { Semptom İndeksi }\end{array}$ & $0-150$ & $0-117$ & $32,54 \pm 29,1$ & \\
\hline
\end{tabular}

Tablo 3. Hastaların yaşadıkları semptomların dağılımı

\begin{tabular}{|c|c|c|c|c|}
\hline \multirow[t]{2}{*}{ Semptomlar } & \multicolumn{2}{|c|}{ Evet } & \multicolumn{2}{|c|}{ Hayır } \\
\hline & $n$ & $\%$ & $n$ & $\%$ \\
\hline Yorgun hissetme veya enerjide azalma & 42 & 57,5 & 31 & 42,5 \\
\hline Ayaklarda uyuşukluk veya karıncalanma & 37 & 50,7 & 36 & 49,3 \\
\hline Ağız kuruluğu & 34 & 46,6 & 39 & 53,4 \\
\hline Kas krampları & 31 & 42,5 & 42 & 57,5 \\
\hline İştahta azalma & 30 & 41,1 & 43 & 58,9 \\
\hline Kemik veya eklem ağrısı & 29 & 39,7 & 44 & 60,3 \\
\hline Uykuya dalmada zorlanma & 28 & 38,4 & 45 & 61,6 \\
\hline Uykuyu sürdürmede zorlanma & 27 & 37,0 & 46 & 63,0 \\
\hline Kaygılı hissetme & 27 & 37,0 & 46 & 63,0 \\
\hline Üzgün hissetme & 26 & 35,6 & 47 & 64,4 \\
\hline Öksürme & 25 & 34,2 & 48 & 65,8 \\
\hline Sinirli hissetme & 24 & 32,9 & 49 & 67,1 \\
\hline Kaşıntı & 24 & 32,9 & 49 & 67,1 \\
\hline Rahatsız hissetme & 23 & 31,5 & 50 & 68,8 \\
\hline Nefes darlığı & 22 & 30,1 & 51 & 69,9 \\
\hline Deride kuruluk & 22 & 30,1 & 51 & 69,9 \\
\hline Kabızlık & 21 & 28,8 & 52 & 71,1 \\
\hline Bacaklarda şişlik & 21 & 28,8 & 52 & 71,2 \\
\hline Baş ağrısı & 21 & 28,8 & 52 & 71,2 \\
\hline Endişelenme & 21 & 28,8 & 52 & 71,2 \\
\hline Sersemlik/baş dönmesi & 21 & 28,8 & 52 & 71,2 \\
\hline Bacakları hareketsiz tutmada zorlanma & 20 & 27,4 & 53 & 72,6 \\
\hline Sekse ilgide azalma & 19 & 26,0 & 54 & 74,0 \\
\hline Konsantre olmada zorluk & 18 & 24,7 & 55 & 75,3 \\
\hline İshal & 18 & 24,7 & 55 & 75,3 \\
\hline Bulantı & 17 & 23,3 & 56 & 76,7 \\
\hline Cinsel yönden uyarılmada zorluk & 16 & 21,9 & 57 & 78,1 \\
\hline Kas ağrısı & 15 & 20,5 & 58 & 79,5 \\
\hline Kusma & 14 & 19,2 & 59 & 80,8 \\
\hline Göğüs ağrısı & 13 & 17,8 & 60 & 82,2 \\
\hline
\end{tabular}


Tablo 4. Hastaların tedaviye uyum durumları ile Herth Umut Ölçeği puan ortalaması arasındaki ilişki

Herth Umut Ölçeği

\begin{tabular}{|c|c|c|c|c|}
\hline Özellikler & $n$ & $\%$ & Ort $\pm S S$ & Anlamlılık \\
\hline \multicolumn{5}{|l|}{ Sağlık kontrollerine gitme durumu } \\
\hline Düzenli olarak - doktorun önerdiği tarihte & 61 & 83,6 & $63,18 \pm 20,51$ & \multirow{2}{*}{$-2,718 / 0,007^{\star *}$} \\
\hline Düzensiz olarak - şikâyetleri olduğu zaman & 12 & 16,4 & $47,25 \pm 12,92$ & \\
\hline \multicolumn{5}{|c|}{ Kan tahlili, kan basıncı ölçümü gibi rutin kontrolleri yaptırma durumu } \\
\hline Doktor istediği takdirde hepsini eksiksiz yaptıır & 64 & 87,7 & $63,73 \pm 19,27$ & \multirow{3}{*}{$13,035 / 0,001^{* *}$} \\
\hline Doktor istemesine rağmen yaptırmadığı rutin kontroller olur & 7 & 9,6 & $37,42 \pm 12,93$ & \\
\hline Doktor istemesine rağmen şikâyet yoksa yaptırmaz & 2 & 2,7 & $40,00 \pm 0,00$ & \\
\hline \multicolumn{5}{|l|}{ İlaçlarını kullanma şekli } \\
\hline Düzenli & 69 & 94,5 & $61,07 \pm 20,29$ & \multirow{4}{*}{$-1,104 / 0,282$} \\
\hline Düzensiz, aklına geldikçe & 4 & 5,5 & $51,75 \pm 20,74$ & \\
\hline Düzensiz, şikâyetleri olduğu zaman & 0 & 0 & - & \\
\hline Kullanmıyor & 0 & 0 & - & \\
\hline \multicolumn{5}{|l|}{ Hastalığınızın yönetimi konusunda diyetini uygulama durumu } \\
\hline Düzenli & 41 & 56,2 & $64,48 \pm 20,93$ & \multirow{4}{*}{$8,346 / 0,039 *$} \\
\hline Düzensiz, aklına geldikçe & 12 & 16,4 & $47,75 \pm 20,38$ & \\
\hline Düzensiz, şikâyetleri olduğu zaman & 3 & 4,1 & $62,33 \pm 9,81$ & \\
\hline Uygulamıyor & 17 & 23,3 & $58,05 \pm 16,24$ & \\
\hline \multicolumn{5}{|l|}{$\begin{array}{l}\text { Hastalığınızın yönetimi konusunda sıvı kısıtlamasını ya da } \\
\text { sıvı alımını uygulama durumu }\end{array}$} \\
\hline Düzenli & 57 & 78,1 & $68,25 \pm 20,46$ & \multirow{4}{*}{$8,040 / 0,045^{\star}$} \\
\hline Düzensiz, aklına geldikçe & 5 & 6,8 & $35,40 \pm 22,51$ & \\
\hline Düzensiz, şikâyetleri olduğu zaman & 4 & 5,5 & $62,49 \pm 19,81$ & \\
\hline Uygulamıyor & 7 & 9,6 & $58,42 \pm 10,92$ & \\
\hline \multicolumn{5}{|l|}{ Baş ağrısı, bulantı, uykusuzluk, kaşıntı gibi yakınmalarda tutumu } \\
\hline Doktorunu ya da hemşiresini telefonla arama & 23 & 31,5 & $65,78 \pm 20,50$ & \multirow{4}{*}{$3,508 / 0,320$} \\
\hline Tedavi gördüğü kuruma gitme & 24 & 32,9 & $59,79 \pm 18,67$ & \\
\hline Kendisi çözme & 22 & 30,1 & $55,86 \pm 22,86$ & \\
\hline Yakınlarına danışma & 4 & 5,5 & $61,00 \pm 9,30$ & \\
\hline
\end{tabular}

\section{Tartışma}

Hayat kurtarıcı olmakla birlikte hemodiyaliz tedavisi, yarattığı fiziksel, psikolojik, sosyal ve ekonomik sorunlar nedeniyle hastaların umut düzeylerini olumsuz etkileyebilmektedir (4). Araştırmada yanıtı aranan ilk soru "Hemodiyaliz hastalarının umut düzeyi nedir?" idi. Çalışmada bulgular doğrultusunda hastaların umut düzeylerinin ortalamadan yüksek olduğu söylenebilir. Araştırma bulgusuna paralel olarak yapılan başka çalışmalarda da hemodiyaliz hastalarının umut düzeylerinin ortalamanın üzerinde olduğu tespit edilmiştir $(4,6,12,13)$. Brezilya'da yapılan bir çalışmada da, çoğu hastada (\%89) minimal düzeyde umutsuzluk belirtilerinin olduğu belirlenmiştir (16). Bu çalışmaların aksine Orlandi ve ark.'nın (2012) çalışmasında, hastaların umut düzeylerinin düşük olduğu belirlenmiştir (10). Araştırma bulgusunun, hastaların ileri yaşta olmaması ve hemodiyalize başlama sürelerinin uzun olmaması gibi faktörlerden kaynaklı olabileceği düşünülmektedir.

Hemodiyaliz tedavisi gören hastalar, hem hastalığa hem de tedaviye bağlı birçok semptom yaşamaktadırlar $(12,30)$. Araştırmada yanıtı aranan ikinci soru "Hemodiyaliz hastalarının semptomlarla ilişkili sıkıntı yaşama düzeyleri nedir?" şeklindedir. Araştırmada hastaların fiziksel ve emosyonel semptomlarla ilişkili yaşanan sıkıntı düzeylerinin düşük olduğu, bununla birlikte en sık karşılaşılan 
semptomların yorgun hissetme veya enerjide azalma, ayaklarda uyuşukluk veya karıncalanma ve ağız kuruluğu olduğu belirlenmiştir. Akgöz ve Arslan'ın (2017) çalışmasında, hastaların semptomları orta düzeyde yaşadıkları, yorgun hissetme ve enerjide azalma, baş ağrısı, kemik ve eklem ağrısının hastalar tarafından en çok deneyimlenen semptom olduğu belirtilmiştir (5). Başka bir çalışmada, hastaların semptomlarla ilişkili yaşadıkları sıkıntı düzeylerinin düşük olduğu ve en sık yorgunluk (\%77), uyku problemleri (\%63) ve kramp (\%52) deneyimledikleri saptanmıştır (31). İran'da yapılan bir çalışmada ise, hastaların Kronik Hemodiyaliz Hastalarında Diyaliz Semptom İndeksi puan ortalaması $(98,85 \pm 23,77)$ yüksek bulunmuş ve hastaların en sık yorgunluk $(\% 85,3)$ ve sinirlilik $(\% 77,9)$ deneyimledikleri belirtilmiştir (8). Murtagh ve ark.'nın (2007) yapmış olduğu sistematik incelemede yorgunluk \%71 (\%12-\%97), kaşıntı \%55 (\%10-\%77), konstipasyon \%53 (\%8-\%57), anoreksi \%49 (\%25-61) ve ağrı \%47 (\%8-82) bildirilmiştir (7). Yapılan başka çalışmalarda da hemodiyaliz hastalarında yorgunluk semptomunun ilk sırada yer aldığı saptanmış $(8,9,31,32)$ ve bu semptom nedeniyle bireylerin yaşam kalitesinin olumsuz etkilendiği tespit edilmiştir (3). Çalışma bulgusuna göre, hastaların semptomlara bağlı düşük düzeyde sıkıntı yaşaması, genel sağlık durumları ve hastalık yönetimi açısından olumlu bir etken olarak değerlendirilmektedir. Bununla birlikte, hastaların en sık karşılaştıkları semptom olan yorgunluk ile baş etmelerini kolaylaştıracak uygulamalar açısından desteklenmesi gerektiği düşünülmektedir.

Hemodiyaliz hastalarında tedavide başarı büyük ölçüde hastaların tedaviye uyumuna bağlıdır (33). Dünya genelinde diyaliz tedavisine uyum oranlarının $\% 8,5-86$ arasında değişkenlik gösterdiği, hemodiyaliz hastalarında uyumsuzluk oranlarının ilaç tedavisinde $\% 15,4-50,2$, sıvı kısıtlamasında \%9,7-49,5 ve diyette \%9-22,1 oranlarında olduğu belirtilmektedir (19). Araştırma sorularından biri olan "Hemodiyaliz hastalarının tedaviye uyumları nasıldır?" sorusuna yönelik hastaların verdiği yanıtlar değerlendirildiğinde, doktorun önerdiği tarihte düzenli olarak sağlık kontrollerine gitme ve kan tahlili, kan basıncı ölçümü gibi rutin kontrolleri eksiksiz yaptırma ile ilaçlarını düzenli kullanma açısından uyumun yüksek olduğu belirlenmiştir. ABD'de 151 hemodiyaliz hastasıyla yapılan bir çalışmada, hastaların çoğunluğu düzenli ilaç kullanmanın önemine sahip olmalarına rağmen, yaklaşık beşte birinin unutkanlık nedeniyle ilaçları önerildiği şekilde almakta zorluk yaşadıklarını ifade ettikleri saptanmıştır (25). Bland ve ark.'nın (2008) çalışmasında da, hastaların yaklaşık üçte birinin ilaç tedavisine uyum sağlamadığı belirlenmiştir (18).
Çalışmada, hastaların sağlık kontrolü ve ilaç kullanımı ile ilgili uyumlarının yüksek olmasına rağmen; diyet ve sıvı kısıtlamasına uyumlarının düşük olduğu, yarısının diyetine dikkat ettiği ve sadece dörtte üçünün sıvı kısıtlamasına uyum sağladığı tespit edilmiştir. Başka bir çalışmada, hemodiyaliz hastalarında diyete uyumun $\% 68,2$, sıvı kısıtlamasına uyumun \%79,5 oranında olduğu belirlenmiştir (25). Benzer şekilde yapılan diğer çalışmalarda da, hastaların yarıdan fazlasının diyet ve sıvı kısıtlamasına uyum sağlayamadığı belirlenmiştir $(27,33,34)$. Efe ve Kocaöz'ün (2015) çalışmasında da, hastaların tamamına yakınının diyetine ve sıvı kısıtlamasına uyumsuzluk gösterdiği tespit edilmiştir (26). Literatürde, tat duyusu bozuklukları, diyabet, kardiyovasküler hastalıklar, gastrointestinal hastalıklar gibi durumların varlığı, yanlış algılama, unutkanlık, bıkkınlık veya hasta yakınlarının yetersiz destekleri gibi nedenlerle hemodiyaliz hastalarının diyet ve sıvı kısıtlamasına tam olarak uyum sağlayamadıkları belirtilmektedir (35). Bu nedenlere ek olarak, hastaların her gün aynı tür yemekleri yemekten sıkılması, sevmediği besin grubunun diyette yer alması, su içme ihtiyacı yaşaması gibi durumların da hastaların diyet ve sıvı kısıtlamasına uyumunu güçleştirebileceği düşünülmektedir. Çalışma bulguları, hemodiyaliz hastalarının beslenme ve sıvı kısıtlamasına uyum yönünde, davranış değişikliği konusunun ısrarla ele alınması gereken, uğraş isteyen ve üzerinde durulması gereken bir tedavi/bakım basamağı olduğuna vurgu yapmaktadır. Tedavi ekibindeki sağlık profesyonellerinin, hastaları çok iyi tanıması, bireysel faktörlerin farkında olması, uyum sorununa neden olan zayıf noktaları bulması, aile içi destek sistemlerinden yararlanması ve olumlu davranışı pekiştirme yönünde mücadele etmelerinde hastalara destek olmaları oldukça önemlidir.

Çalışmada yanıtı aranan sorulardan birisi "Hemodiyaliz hastalarının umut düzeyleri ile semptom kontrolü arasında bir ilişki var mıdır?" idi. Çalışmada, umut düzeyi arttıkça fiziksel ve emosyonel semptomlarla ilişkili yaşanan sıkıntı düzeyinin azaldığı belirlenmiştir. Umut terapisinin hemodiyaliz hastalarında depresyon, anksiyete ve stres üzerine etkisinin incelendiği bir çalışmada, umut terapisi alan grubun plasebo grubuna göre depresyon, anksiyete ve stres düzeylerinin daha düşük olduğu tespit edilmiştir (1). Başka bir çalışmada da, umudun diyaliz tedavisi olan hastaların semptom yönetimine önemli bir belirleyici olduğu vurgusu yapılmıştır (6). Çalışma bulgusu hastaların umut düzeylerini artırmaya yönelik yapılacak uygulamalar ile hastalık ve hemodiyalize bağlı semptomların kontrol altına alınabileceğini göstermektedir. 
Hemodiyaliz hastalarında tedaviye uyumu sağlık inançları, hastalık ve tedavi süreci üstünde kontrol algısı, kültürel özellikler, stres, depresyon, sosyal destek ve sağlık personelinden memnuniyet gibi faktörler etkileyebilmektedir (17). Çalışmada yanıtı aranan son soru “Hemodiyaliz hastalarının umut düzeyleri ile tedaviye uyum arasında bir ilişki var mıdır?" sorusudur. Çalışmada umut düzeyi yüksek olan hastaların doktorun önerdiği tarihte düzenli olarak sağlık kontrollerine gitme, kan tahlili, kan basıncı ölçümü gibi rutin kontrolleri eksiksiz yaptırma, hastalığının yönetimi konusunda diyetini düzenli uygulama ve sıvı kısıtlamasına ya da sıvı alımına dikkat etme gibi tedaviye uyumlarının daha iyi olduğu belirlenmiştir. Çalışma bulgusu, hastaların tedaviye uyumlarını artırmada umudun da etkili olabileceğini göstermektedir. Özellikle hasta ile uzun süre vakit geçiren hemşirelerin sosyal ve psikolojik destek uygulamalarını içeren girişimler ile hastaların umut düzeylerini iyileştirmesi önemlidir.

\section{Sonuç}

Elde edilen bulgular doğrultusunda hastaların diyet ve sıvı kısıtlamasına yönelik tedaviye uyumun istenilen düzeyde

\section{Kaynaklar}

1. Rahimipour M, Shahgholian N, Yazdani M. Effect of hope therapy on depression, anxiety, and stress among the patients undergoing hemodialysis. Iranian J Nurs Midwifery Resh 2015;20:694-99. [CrossRef]

2. Seyani N, Ateş K, Süleymanlar G. Türkiye'de renal replasman tedavilerinin güncel durumu: Türk Nefroloji Derneği kayıt sistemi 2015 yılı özet raporu. Turk Neph Dial Transpl 2017;26:154-60. [CrossRef]

3. Davison SN, Jhangri GS. Impact of pain and symptom burden on the health-related quality of life of hemodialysis patients. J Pain Symptom Manage 2005;39:477-85. [CrossRef]

4. Park GY, Yoo EK. A study on hope in hemodialysis patients. Adv Sci Technol Lett (Healthcare and Nursing 2016);128:244-6. [CrossRef]

5. Akgöz N, Arslan S. Hemodiyaliz tedavisi alan hastalarda yaşanan semptomların incelenmesi. Nefroloji Hem Derg 2017:1:20-8. Erişim: https://dergipark.org.tr/tr/download/article-file/360008

6. Billington E, Simpson J, Unwin J, Bray D, Giles D. Does hope predict adjustment to end-stage renal failure and consequent dialysis? $\mathrm{Br} J$ Health Psychol 2008;13:683-99. [CrossRef]

7. Murtagh FEM, Addington-Hall J, Higginson IJ. The prevalence of symptoms in end-stage renal disease: A systematic review. Adv Chronic Kidney Dis 2007;14:82-99. [CrossRef]

8. Zamanian $\mathrm{H}$, Kharameh ZT. Translation and psychometric properties of the persian version of the dialysis symptom index in hemodialysis patients. Nephro Urol Mon 2015;7:e23152. [CrossRef]

9. Akin S, Mendi B, Ozturk B, Cinper C, Durna Z. Assesment of relationship between self-care and fatigue and loneliness in hemodialysis patients. J Clin Nurs 2014;23:856-64. [CrossRef] olmadığı, umut düzeyinin semptomlarla ilişkili sıkıntı düzeyini ters yönde ve tedaviye uyumunu pozitif yönde etkilediği saptanmıştır. Bu doğrultuda umudun semptom kontrolünü ve tedaviye uyumu sağlamada etkili olabileceği söylenebilir.

Hemodiyaliz hastalarının umut düzeylerini korumak ve iyileştirmek için, hemşirelere hastaların duygularını ifade etmesine olanak sağlayacak düzenli görüşmeler yapması, gezi, kutlama gibi sosyal aktivite programları oluşturması, hastaların bakımında aile üyelerinin desteğini sağlaması, hastalara başa çıkma becerileri öğretmesi yönünde uygulamalar yapması önerilmektedir. Ayrıca, hastaların umut düzeylerini iyileştirmeye yönelik hemodiyaliz ünitelerinde görev yapan hemşirelere yönelik hizmet içi eğitim programlarının düzenlenmesi katkı sağlayabilir. Ek olarak hastaların diyet ve sıvı kısıtlamasına uyumlarını artırmak amacıyla hastaya uygun öğretim materyalleri kullanılarak ve tedaviye uyumun etkisini vurgulayarak bireysel eğitim programlarının oluşturulması, düzenli aralıklarla hastaların tedaviye uyumlarının değerlendirilmesi, eksikliklerin saptanması ve alternatif uygulamaların hastaya öğretilmesi faydalı olabilir.

10. Orlandi FS, Pepino BG, Pavarini SCl, dos Santos DA, de Mendiondo MSZ. The evaluation of the level of hope of elderly chronic kidney disease patients undergoing hemodialysis. Rev Esc Enferm USP 2012;46:897901. Erişim: http://www.scielo.br/pdf/reeusp/v46n4/en_17.pdf

11. Topbaş E, Bingöl G. Psikososyal boyutu ile diyaliz tedavisi ve uyum sürecine yönelik hemşirelik girişimleri. Nefrol Hem Derg 2017:1:3642. Erişim: https://dergipark.org.tr/tr/download/article-file/363922

12. Melo GAA, Silva RA, da Silva MFC, Galvao MTG, da Silva VM, Caetano JA. Religiosity and hope in patients with chronic renal failure: coping strategies. Int Arch Med 2016;9:1-9. [CrossRef]

13. Ottaviani AC, Souza EN, Drago NC, Mendiondo MSZ, Pavarini SCl, Orlandi FS. Hope and spirituality among patients with chronic kidney disease undergoing hemodialysis: a correlational study. Rev Latino-Am Enfermagem 2014;22:248-54. [CrossRef]

14. Cutcliffe JR, Herth KA. The concept of hope in nursing 2: hope and mental health nursing. Br J Nurs 2002;11:885-93. [CrossRef]

15. Saran R, Bragg-Gresham JL, Rayner HC, Goodkin DA, Keen ML, van Dijk PC, et al. Nonadherence in hemodialysis: associations with mortality, hospitalization, and practice patterns in the DOPPS. Kidney Int 2003;64:254-62. [CrossRef]

16. Andrade SV, Sesso R, Diniz DHMP. Hopelessness, suicide ideation, and depression in chronic kidney disease patients on hemodialysis or transplant recipients. J Bras Nefrol 2015:37:55-63. [CrossRef]

17. Kara B. Hemodiyaliz hastalarında tedaviye uyum: Çok yönlü bir yaklaşım. Gülhane Tıp Derg 2007;9:132-6. Erişim: http:// gulhanemedj.org/uploads/pdf/pdf_GMJ_364.pdf

18. Bland RJ, Cortrell RR, Guyler LR. Medication compliance of hemodialysis patients and factors contributing to non-compliance. Dial Transpl 2008;37:174-8. [CrossRef] 
19. Matteson ML, Russel C. Interventions to improve hemodialysis adherence: A systematic review of randomized-controlled trials. Hemodial Int 2010;14:370-82. [CrossRef]

20. Clark S, Farrington K, Chilcot J. Nonadherence in dialysis patients: prevalence, measurement, outcome, and psychological determinants. Semin Dial 2014;27:42-9. [CrossRef]

21. Kammerer J, Garry G, Hartigan M, Carter B, Erlich L. Adherence in patients on dialysis: strategies for success. Nephrol Nurs J 2007;34:479-86.

22. Kavradım ST, Özer ZC. Kanser tanısı alan hastalarda umut. Curr Approach Psychiatr 2014;6:154-64. [CrossRef]

23. Kukla M, Salyers MP, Lysaker PH. Levels of patient activation among adults with schizophrenia: associations with hope, symptoms, medication adherence, and recovery attitudes. J Nerv Ment Dis 2013;201:339-44. [CrossRef]

24. Ripamonti Cl, Miccinesi G, Pessi MA, Di Pede P, Ferrari M. Is it possible to encourage hope in non-advanced cancer patients? We must try. Ann Oncol 2016;27:513-9. [CrossRef]

25. Kim Y, Evangelista LS. Relationship between ıllness perceptions, treatment adherence, and clinical outcomes in patients on maintenance hemodialysis. Nephrol Nurs J 2010;37:271-81. Erişim: https://www.ncbi.nlm.nih.gov/pmc/articles/PMC3172671/

26. Efe D, Kocaöz S. Adherence to diet and fluid restriction of individuals on hemodialysis treatment and affecting factors in Turkey. Japan J Nurs Sci 2015;12:113-23. [CrossRef]

27. Mollaoğlu M, Kayataş M. Disability is associated with nonadherence to diet and fluid restrictions in end-stage renal disease patients undergoing maintenance hemodialysis. Int Urol Nephrol 2015;47:1863-70. [CrossRef]
28. Aslan Ö, Sekmen K, Kömürcü Ş, Özet A. Kanserli hastalarda umut. CÜ Hem YO Derg 2007;11:18-24. Erişim: http://eskidergi.cumhuriyet. edu.tr/makale/1610.pdf

29. Önsöz HB, Usta Yeşilbalkan Ö. Reliability and validity of the Turkish version of the Dialysis Symptom Index in chronic hemodialysis patients. Turk Neph Dial Transpl 2013;22:60-7. [CrossRef]

30. Thong MS, Van Dijk S, Noordzij M, Boeschoten EW, Krediet RT, Dekker FW, Kaptein AA; Netherlands Cooperative Study on the Adequacy Study Group. Symptom clusters in incident dialysis patients: associations with clinical variable sand quality of life. Nephrol Dial Transpl 2009;24:225-30. [CrossRef]

31. Jablonski A. The multidimensional characteristics of symptoms reported by patients on hemodialysis. Nephrol Nurs J 2007;34:29-38.

32. Yu IC, Huang JY, Tsai YF. Symptom cluster among hemodialysis patients in Taiwan. Appl Nurs Res 2012;25:190-6. [CrossRef]

33. Günalay S, Taşkıran E, Mergen H. Hemodiyaliz hastalarında diyet ve sıvı kısıtlamasına uyumsuzluğunun değerlendirilmesi. FNG \& Bilim Tıp Derg 2017;3:9-14. [CrossRef]

34. Kugler C, Vlaminck H, Haverich A, Maes B. Nonadherence with diet and fluid restrictions among adults having hemodialysis. J Nurs Scholarsh 2005;37:25-9. [CrossRef]

35. Elmas A. Saral EE, Tuğrul A, Şengül E, Bülbül F. Hemodializ hastalarında beslenme bilgi düzeyi ile klinik ve laboratuar bulguları arasındaki ilişki. Kocaeli Tıp Derg 2012;3:23-6. Erişim: http://www. journalagent.com/kocaelitip/pdfs/KTD_1_3_23_26.pdf 